\title{
국소 근염에 의한 머리떨굼증후군
}

조정희, 김규식, 김종헌, 이준홍, 이지은

국민건강보험 일산병원 신경과

\section{A Case of Dropped Head Syndrome Caused by Focal Myositis}

\author{
Jeong Hee Cho, Gyu Sik Kim, Jong Hun Kim, Jun Hong Lee, Jieun Lee \\ Department of Neurology, National Health Insurance Service Ilsan Hospital, Goyang, Korea
}

\begin{abstract}
Dropped head syndrome is characterized by restricted weakness of the extensors of the neck. It can be caused by many neuromuscular disorders. We present a case of dropped head syndrome by focal myositis. A 73-year-old man had a difficulty in maintaining an erect posture of his neck and lifting his chin off the chest. These symptoms developed gradually over 11 months. The EMG of the bilateral cervical paraspinal muscles demonstrated fibrillation potentials and positive sharp waves. The MRI revealed a diffuse edema of the neck extensor muscles on T2-weighted images and gadolinium enhancement. The neck extensor weakness improved significantly after treatment of steroids. Dropped head syndrome is a rare condition and in a subgroup of patients it is caused by a focal myositis. The findings of EMG and MRI can give us make a diagnosis of focal myositis and be a rationale for use of steroids.
\end{abstract}

Key Words: dropped head syndrome, myositis

\section{서 론}

머리떨굼증후군(dropped head syndrome)은 목폄근 (neck extensor)의 약화로 인해 서거나 앉아있을 때 머리가 점차 아래로 쳐지고 머리를 들지 못하는 상태로, 일상생활의 장애를 초래한다. ${ }^{1-3}$ 머리떨굼증후군은 다양한 신경근육질환 에 의해 발생할 수 있고, 다른 원인질환 없이 단독으로 나타 날 수도 있다. ${ }^{1,3}$ 저자들은 스테로이드에 반응을 보인 목폄근

Received October 31, 2017

Revised December 18, 2017

Accepted January 19, 2018

Corresponding Author: Jeong Hee Cho

Department of Neurology, National Health Insurance Service Ilsan

Hospital, 100 Ilsan-ro, Ilsandong-gu, Goyang 10444, Korea

Tel: 82-31-900-3026, Fax: 82-31-900-0343, E-mail: jhcho.neuro@gmail.com
의 국소 근염에 의한 머리떨굼증후군 증례를 경험하였기에 보고하고자 한다.

\section{증 례}

73세 남자가 11 개월전부터 목을 뒤로 젖히기 힘들고, 목 이 앞으로 숙여지는 증상이 점차 심해져서 내원하였다. 과거 력상 18 년전 뇌경색 이후 좌하지 근력약화가 있고, 12 년전 부터 기억력장애가 있고, 8년전 넘어진 후 발생한 경막하혈 종에 대해 단순천공배액술을 시행 받았고, 고혈압약을 복용 중이었다. 머리떨굼은 하루변이가 없었고 눈꺼풀처짐이나 복시도 없었다. 신경학적 진찰상 환자는 고개를 앞으로 떨군 상태였고(Fig. $1 \mathrm{~A}$ ) 목의 굽힘은 정상이었으나 폄은 $\mathrm{MRC}$ 등 급 2였다. 이외에 좌하지 근위부의 근력이 $\mathrm{MRC}$ 등급 4이고
Copyright $\odot$ by Korean Association of EMG Electrodiagnostic Medicine
This is an Open Access article distributed under the terms of the Creative Commons Attribution Non-Commercial License (http://creativecommons.org/licenses/by-nc/4.0) which permits unrestricted non-commercial use, distribution, and reproduction in any medium, provided the original work is properly cited. 

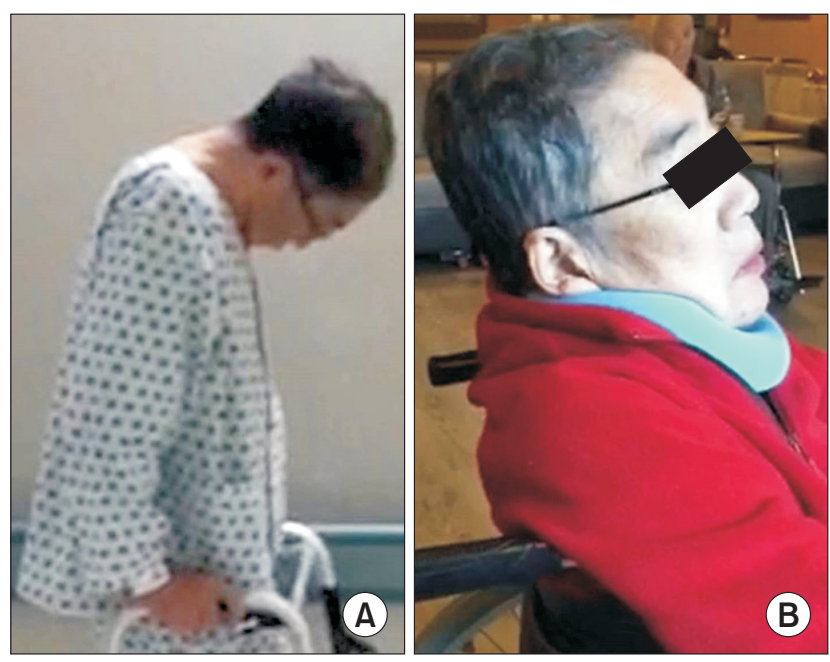

Fig. 1. (A) The patient had dropped head while walking before treatment. (B) He could keep his head upright during daily activities after two months of treatment.
좌하지의 건반사가 항진되어 있었으며, 양상지와 우하지의 근력은 정상이었다. 혈액검사상 크레아틴키나아제는 109 $\mathrm{U} / 1$ 로 정상범위였고 $\mathrm{ESR}, \mathrm{CRP}$, 갑상선호르몬도 모두 정상 이었다. 정중신경, 자신경, 종아리신경, 정강신경 및 장딴지 신경에서 시행한 신경전도검사상 운동신경 및 감각신경 활 동전위 및 전도속도는 모두 정상이었고, 근전도검사상 양쪽 C5-8 척추옆 근육에서 심한 섬유자발전위와 양성예파가 관 찰되었고 상하지의 근육은 정상이었다(Table 1). 경추 자기 공명영상은 T2 강조영상에서 머리널판근(splenius capitis muscle) 의 국소 부종을 보이고 가돌리늄 투여 후 T1 강조 영상에서 조영증강을 보였다(Fig. 2).

환자는 5일간 고용량의 스테로이드 정맥 투여 후 경구 프 레드니솔론과 아자티오프린을 복용하였다. 환자는 목폄근 의 근력이 점차 호전되어 치료 2개월 후 고개를 떨구지 않고

Table 1. Needle Electromyography

\begin{tabular}{|c|c|c|c|c|}
\hline Muscle & Insertion activity & Spontaneous activity & MUAPs & Recruitment pattern \\
\hline Left FDI, BB, TA, VL & Increased & None & Normal & Normal \\
\hline Bilateral CPSM (C5-8) & Increased & Fib \& PSW & NC & NC \\
\hline
\end{tabular}

MUAPs: motor unit action potentials, FDI: first dorsal interossei muscle, BB: biceps brachii muscle, TA: tibialis anterior muscle, VL: vastus lateralis muscle, CPSM: cervical paraspinal muscles, Fib: fibrillation potentials, PSW: positive sharp waves, NC: not checkable
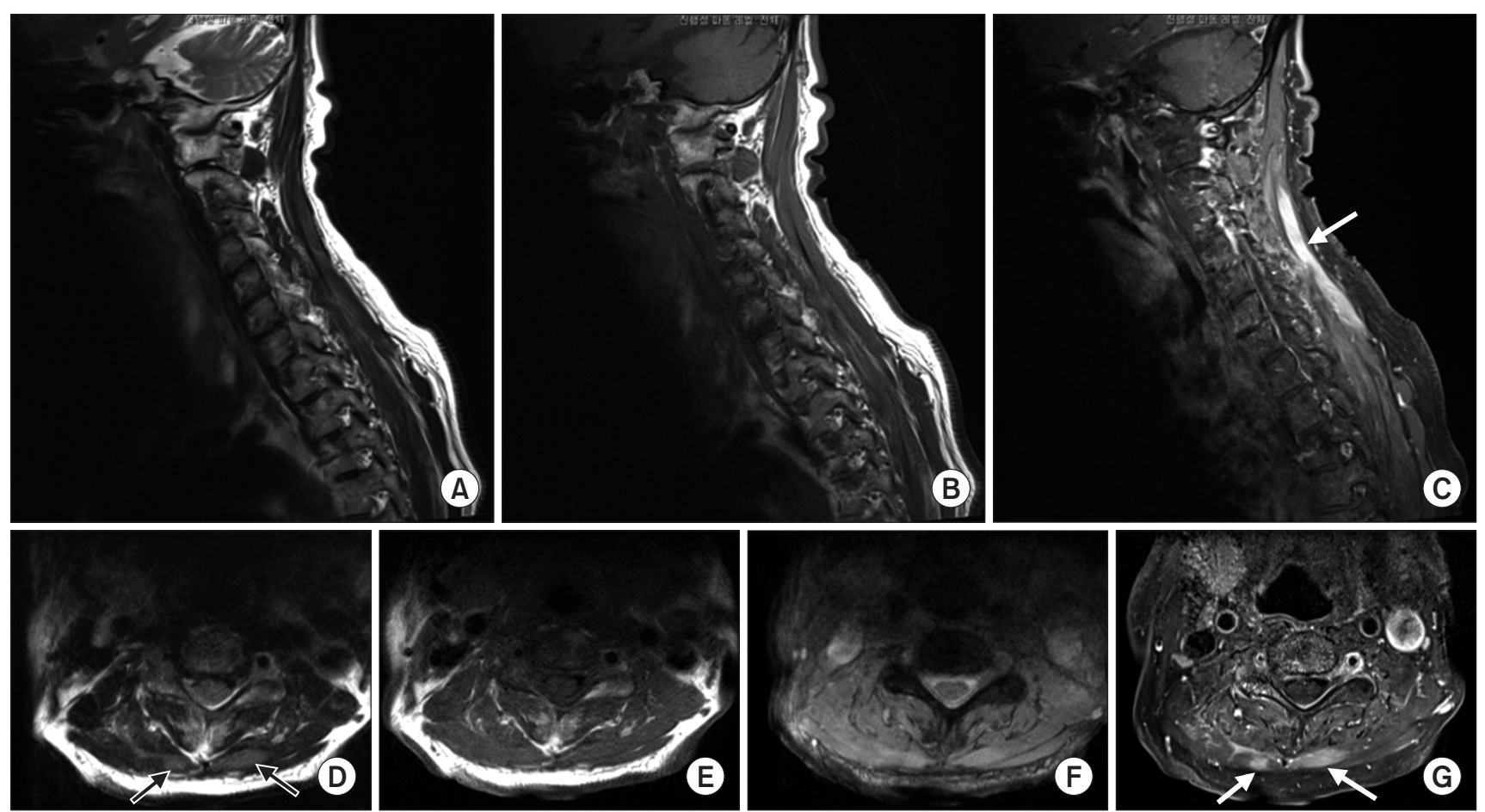

Fig. 2. MRI demonstrated focal hyperintensity of bilateral splenius capitis muscles on T2-weighted images, as well as enhancement of those muscles after administration of gadolinium on T1-weighed images. (A, D) T2-weighted images, (B, E) T1-weighted images, (C, G) gadoliniumenhanced T1-weighed images, (F) fat-suppressed T1-weighted image. 
일상생활을 할 수 있었다(Fig. 1B). 이후 환자는 내원하지 않 았고 요양원에서 사망하였다고 한다.

\section{고 찰}

머리떨굼증후군은 목폄근의 근력약화로 인해 서거나 앉아 있을 때 머리가 점차 아래로 쳐지고 심하면 턱이 가슴에 당 는 변형(chin-on-chest deformity)까지 발생할 수 있는 상 태로, 경추뒤굽음변형(cervical kyphotic deformity)과 달 리 수동적으로는 목을 펼 수 있다. ${ }^{1-3}$ 머리떨굼증후군 환자는 시선이 아래로 떨구어져서 앞을 제대로 보지 못하고 음식을 삼키기가 어려울 수도 있다. 그리고 환자들은 일상생활의 장 애뿐만 아니라 사회적 상호관계에도 어려움을 느낀다. ${ }^{1}$

머리떨굼증후군을 유발하는 흔한 신경근육질환으로 근 위축측삭경화증, 염증근육병(다발근염, 피부근염, 봉입체근 염), 중증근무력증이 있고, 드물게 만성염증탈수초다발신경 병, 대사이상(갑상선저하증, 쿠싱증후군, 부갑상선항진증), 네말린 근병증, 미토콘드리아근육병, 카르니틴결핍근육병 등에서도 머리떨굼증후군이 나타날 수 있다. 1,3 신경근육질 환 외에도 다계통위축증과 파킨슨병, ${ }^{4-6}$ 방사선 치료의 합병 증 $7-9$ 으로 머리떨굼증후군이 발생할 수 있다.

다른 원인질환 없이 머리떨굼증후군이 단독으로 나타 날 수 있는데, ${ }^{10,11}$ 이를 단독목폄근근육병(isolated neck extensor myopathy, 이하 INEM)이라 한다. INEM은 일 반적으로 64 85세에 아급성으로 나타나며 근력약화가 3 개월 후에 안정기에 접어드는 양성의 경과를 보인다. ${ }^{1,10,11}$ INEM이 나타나는 기전은 확실하지 않지만 흥추뒤굽음증 (thoracic kyphosis)과 조직 탄성의 소실에 의한 목척추주 위근의 기계적인 손상이 원인이라는 가설이 가장 널리 받아 들여진다. ${ }^{2,3,10}$ 나이가 들면 흥추뒤굽음증이 증가하고 척주 가 지탱하는 머리의 무게 중심이 척추의 축 앞쪽으로 이동하 고 이로 인해 목척추주위근에 가해지는 스트레스가 증가한 다. ${ }^{3}$ 조직 탄성의 소실에 따라 목척추주위근이 늘어나고 피 로가 발생하게 되고, 지속적인 손상과 근력약화가 결국 불 가역적인 변화를 초래한다는 것이다. ${ }^{2} \mathrm{INEM}$ 이 전형적으로 60세 이상의 환자에서 발생하며 50세 이전에는 거의 나타 나지 않고 ${ }^{10,11}$ 경추옆근육의 생검상 비특이적인 비염증근병 소견인 섬유증, 섬유크기의 다양성 증가, 근원섬유 비정렬 (myofibrillar disarray)을 보이는 것은 이를 뒷받침하는 증 거가 될 수 있다. ${ }^{1,12-15}$ 대부분의 INEM 환자는 회복되지 않고 스테로이드 치료에 대한 반응도 좋지 않다. ${ }^{1,2}$
머리떨굼증후군의 치료로 물리치료와 경추보호대 등의 보 존적인 치료와 수술적인 치료가 있다. 물리치료로 머리떨굼 증후군이 호전된 보고도 있으나 ${ }^{16}$ 대부분의 연구에서 물리치 료는 증상을 호전시키지 못했고, 경추보호대는 환자가 전방 주시를 유지하고 일상생활의 활동이 가능하도록 도와준다. ${ }^{2}$ 물리치료와 경추보호대와 같은 보존적인 치료로 실패한 환 자나 삼키는 데 어려움을 겪거나 전방주시를 유지하는 기능 에 제한이 있는 사람들에게는 경추의 수술을 고려할 수 있 다. $2,3,17$

INEM 환자 중 일부는 스테로이드나 면역글로불린 정맥주 사에 대한 반응이 좋은데, 근생검상 목폄근에 염증세포의 침 윤이 현저하다는 공통점이 있고, 국소 근염 혹은 근염에 의 한 머리떨굼증후군으로 보고되었다. ${ }^{18-21}$ 국소 근염은 목폄 근의 근생검을 통해 진단할 수 있으나, 목폄근과 같은 비정 형적인 생검 부위에서 시행한 근생검을 해석하기란 매우 어 렵고 목폄근을 정확하게 생검하는 것도 기술적으로 쉽지 않 다. ${ }^{1}$ 국소 근염에 의한 머리떨굼증후군 환자의 자기공명영상 은 T2 강조영상에서 목폄근의 신호강도가 증가하고 가돌리 늄 투여 후 T1 강조 영상에서 조영증강을 보이는데 이는 염 증근병의 전형적인 소견이다. ${ }^{18,20}$ 본 증례는 근생검을 시행 하지는 않았으나 근전도검사에서 양쪽 척추옆 근육에서만 심한 섬유자발전위와 양성예파가 관찰되고, 자기공명영상 에서 머리널판근에 국한된 염증근병 소견이 관찰되며 스테 로이드 치료 후 증상이 호전된 점을 고려할 때 국소 근염에 의한 머리떨굼증후군의 진단이 가능하겠다.

머리떨굼증후군을 유발하는 목폄근의 국소 근염이 실제 존재하는 하나의 질병인지 다발근염의 일종인지는 확실하 지 않고 염증근병이 왜 목폄근에만 국한되는지에 대한 의문 도 아직 해결되지 않았다. ${ }^{10,18}$

저자들은 국내에서 처음으로 국소 근염에 의한 머리떨굼 증후군을 경험하였기에 보고하는 바이다. 국소 근염에 의한 머리떨굼증후군은 매우 드물지만 치료가 가능한 질환으로, 자기공명영상과 가능하다면 근생검을 통해 진단하려는 노 력이 필요하겠다.

\section{References}

1. Cauchi M, Marsh E: A practical approach to the patient presenting with dropped head. Pract Neurol 2016: 16: 445-451

2. Sharan AD, Kaye D, Charles Malveaux WM, Riew KD: Dropped head syndrome: etiology and management. J Am Acad Orthop Surg 2012: 20: 766-774 
3. Petheram TG, Hourigan PG, Emran IM, Weatherley CR: Dropped Head Syndrome: A Case Series and Literature Review. Spine 2008: 33: 47-51

4. Oyama G, Hayashi A, Mizuno Y, Hattori N: Mechanism and treatment of dropped head syndrome associated with parkinsonism. Parkinsonism Relat Disord 2009: 15: 181-186

5. Ko P, Kang K, Lee H: Fluctuating Pramipexole Induced Dropped Head Syndrome. J Korean Neurol Assoc 2017: 35: 46-47

6. Askmark H, Eeg-Olofsson KE, Johansson A, Nilsson P, Olsson Y, Aquilonius S: Parkinsonism and Neck Extensor Myopathy: A New Syndrome or Coincidental Findings? Arch Neurol 2001: 58: 232-237

7. Rowin J, Cheng G, Lewis SL, Meriggioli MN: Late appearance of dropped head syndrome after radiotherapy for Hodgkin's disease. Muscle Nerve 2006: 34: 666-669

8. Furby A, Béhin A, Lefaucheur J, Beauvais K, Marcorelles P, Mussini J, et al: Late-onset cervicoscapular muscle atrophy and weakness after radiotherapy for Hodgkin disease: a case series. J Neurol Neurosurg Psychiatr 2010: 81: 101-104

9. Lim OK, Shim HY, Yoon JW, Lee JY, Park KD, Lee JK: Dropped Head Syndrome (DHS) Combined with Cervical Polyradiculopathy Following Radiotherapy. J Korean EMG Electrodiagn Med 2014: 16: 70-74

10. Katz JS, Wolfe GI, Burns DK, Bryan WW, Fleckenstein JL, Barohn RJ: Isolated neck extensor myopathy: a common cause of dropped head syndrome. Neurology 1996: 46: 917921

11. Liao JP, Waclawik AJ, Lotz BP, Salamat SM, Beinlich BR, Brooks BR: Myopathic dropped head syndrome: an expanding clinicopathological spectrum. Am J Phys Med Rehabil 2007: 86: 970-976

12. Umapathi T, Chaudhry V, Cornblath D, Drachman D, Griffin
J, Kuncl R: Head drop and camptocormia. J Neurol Neurosurg Psychiatr 2002: 73: 1-7

13. Goh KJ, Wong KT, Tan CT: Myopathic dropped head syndrome: a syndrome of mixed aetiology. J Clin Neuroscience 2000: 7: 334-336

14. Jaster JH, Bertorini TE, Swims MP, Dohan FC, Menke PG, Becske T, et al: Cervical kyphosis after resolution of myopathic head drop. A case report. Spine 1996: 21: 2023-2025

15. Oerlemans WG, de Visser M: Dropped head syndrome and bent spine syndrome: two separate clinical entities or different manifestations of axial myopathy? J Neurol Neurosurg Psychiatr 1998: 65: 258-259

16. Macé Y, Yahia M, Rannou F, Lefevre-Colau MM, Poiraudeau S, Revel M: Value of intensive rehabilitation in fixed dropped head syndrome. Ann Readapt Med Phys 2005: 48: 207-211

17. Mirchandani A, Chen A: Isolated Neck Extensor Myopathy: A Case Presentation of Rapid Onset and Spontaneous Recovery. PM R 2018: 10: 552-554

18. Kastrup A, Gdynia H, Nägele T, Riecker A: Dropped-head syndrome due to steroid responsive focal myositis: A case report and review of the literature. J Neurol Sci 2008: 267: $162-165$

19. Biran I, Cohen O, Diment J, Peyser A, Bahnof R, Steiner I: Focal, steroid responsive myositis causing dropped head syndrome. Muscle Nerve 1999: 22: 769-771

20. Gaeta M, Mazziotti S, Toscano A, Rodolico C, Mazzeo A, Blandino A: "Dropped-head" syndrome due to isolated myositis of neck extensor muscles: MRI findings. Skelet Radiol 2006: 35: 110

21. Dominick J, Sheean G, Schleimer J, Wixom C: Response of the dropped head/bent spine syndrome to treatment with intravenous immunoglobulin. Muscle Nerve 2006: 33: 824826 